\title{
Reliability and Validity of Measurement of Infrasternal Angle by Radio- graphic Methods
}

\author{
Won-hwee Lee, Ph.D \\ Department of Physical Therapy, Vision College of Jeonju, Jeonju, South Korea
}

Background The infrasternal angle is typically measured using goniometric or photographic methods. Because chest anterior-posterior radiographic images cannot be used to identify the xiphoid process, no study has evaluated the validity of infrasternal angle measurement.

Purpose The purpose of this study was to determine reliability and validity of measurement of infrasternal angle by radiographic method.

Study design Intra- and inter-tester repeated measures.

Methods Infrasternal angles were measured in 25 healthy students using goniometric and radiographic method. To check the xiphoid process in radiographs, the examiner set the marker at the xiphoid process. Radiographs were taken by one X-ray technician for each subject using a radiographic apparatus. Repeated radiographs measurements were made in two test sessions conducted on different days by two testers to assess inter-rater and intra-rater reliability. The reliability of the infrasternal angle measurement was using intraclass correlation coefficients (ICCs: 3,1). The correlation between measurements taken by the radiograph and goniometric methods was calculated to test the validity of the radiographic method. The alpha level was set at 0.05 .

Results The intra- and inter-rater reliability of infrastenral angle measurements taken by the radiographic method were excellent (ICC $=0.991$ and 0.993 , respectively). Radiographic measurement of the infrasternal angle was highly correlated with goniometric measurement $(r=0.85)$.

Conclusions We suggest that the radiographic method is a highly reliable and valid tool for infrasternal angle measurement.

JMST

2018; 2(2): 33-37

Published Online

Dec 31, 2018

pISSN 2635-8573

eISSN 2635-8581

\section{Article History}

Received 25 September 2018

Revised 26 September 2018

(1st)

Revised 24 October 2018

(2nd)

Accepted 25 October 2018

\section{CONTACT}

whlee@jvision.ac.kr

Won-hwee Lee,

Department of Physical

Therapy, Vision College

of Jeonju, Jeonju, South

Korea

\section{This is an Open-Access article distributed under the terms of the Creative Commons Att- ribution Non-Commercial Li- cense (http://creativecommons org/licenses/by-nc/4.0) which permits unrestricted non-co- mmercial use, distribution, and reproduction in any me- dium, provided the origina} work is properly cited.

Key words Infrasternal angle; Radiograph; Reliability; Ribcage alignment; Validity.

\section{INTRODUCTION}

The thorax consists of a relatively rigid rib cage, formed by the ribs, thoracic vertebrae, and sternum. ${ }^{1}$ It encloses the thoracic cavity, forming a protective cage for the cardiopulmonary organs, and supports attachment of the diaphragm and trunk muscles such as the internal or external oblique muscles..$^{2-4}$

Changes in the alignment of the thorax has a variety of causes, including congenital chest wall deformities such as pectus excavatum/carinatum and spine deformities such as osteoporosis with excessive kyphosis or scoliosis.,5-8 Asymmetrical lengths of the internal and external oblique muscles between the right and left sides also affect thorax alignment. ${ }^{9}$ In addition, asymmetrical length or activation of the abdominal oblique muscle can cause movement impairment syndrome such as thoracic rotation syndrome or lumbar rotation syndrome. ${ }^{10,11}$

One method used to evaluate thorax alignment is to measure the infrasternal angle, which requires measuring 
the angle between the xiphoid process and the medial margin of the rib on each side. ${ }^{11}$ The ideal infrasternal angle, is considered a reflection of the balance between the lengths of the internal and external oblique muscles. ${ }^{11}$ Contraction of the internal oblique muscles pulls the thorax towards the pelvis and widens the infrasternal angle. However, contraction of the external oblique muscles decreases the infrasternal angle. ${ }^{10}$

Little research has been conducted on measurement of the infrasternal angle. Because chest anterior-posterior (AP) radiographic images cannot be used to identify the xiphoid process, no study has evaluated the validity of infrasternal angle measurement. ${ }^{1}$ Kim et al. ${ }^{1}$ measured the infrasternal angle using photography to investigate intra- and inter-rater reliability. In this study, we used a marker to identify the xiphoid process and measured the infrasternal angle by AP radiographic imagery. Therefore, we used radiographic methods to determine the reliability and validity of measurement of the infrasternal angle measurement.

\section{METHODS}

The subjects were 25 healthy students (11 males, 14 females) aged $22.7 \pm 1.3$ years (mean \pm standard deviation [SD]), with a height of $166.4 \pm 6.2 \mathrm{~cm}$ and body weight of $63.1 \pm 10.7 \mathrm{~kg}$. Subjects had no neuromuscular or cardiopulmonary disorders and no congenital disorders of the trunk such as scoliosis, rib fracture, or pectus excavatum/carinatum. Before participating in the study, the content and experimental procedures of the study were explained to all subjects. All subjects voluntarily participated in this study and signed an informed consent form.

\section{Testing protocol}

All testing procedures were performed in a hook-lying position (Figure 1). The infrasternal angle is the angle formed between the xiphoid process and the medial margin of the $10^{\text {th }}$ rib on each side. ${ }^{11}$ Measurement of the infrasternal angle were conducted using both radiographic and goniometric methods, once for each subject within a session.

\section{Radiographic measurement}

Because radiographic images cannot identify the xiphoid process in chest AP X-rays, to determine the xiphoid process, the examiner set a marker at the xiphoid process. The marker was $8 \mathrm{~mm}$ in diameter. Radiographs were taken by the same X-ray technician using a radiographic apparatus (Beam Limiting device, TOSHIBA Medical Manufacturing Co., Ltd., JAPAN). The subject was asked to lie in hook-

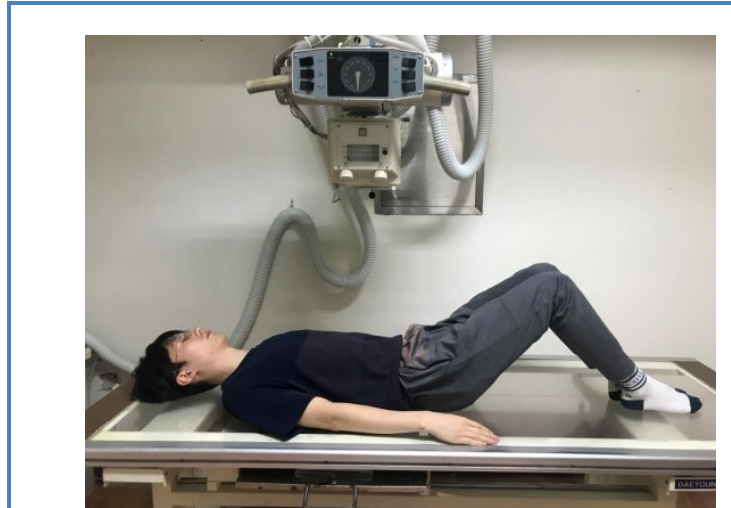

Figure 1. Measurement position.

lying position on a grid, and the X-ray technician placed a grid on the subject's chest. This posture was maintained by all of the subjects during AP radiographs. Because the size of the ribcage changes with respiration, we acquired the x-ray image when the subject held their breath after expiration. All acquired images were analyzed using the FCR viewer program (Fuji Film Co., Ltd., JAPAN). The infrasternal angle was calculated between the center of marker and the medial margin of the $10^{\text {th }}$ rib on each side of the chest X-ray (Figure 2). Infrasternal angle measurement was conducted by two testers. Tester 1 was an experienced therapists who had 10 years of clinical orthopedic physical therapy experience; tester 2 was a sophomore student in the department of physical therapy. Prior to measurements, the testers became acquainted with the infrasternal angle measurement technique and the experimental procedures by sufficient pre-training. Intra-rater reliability was calculated based on measurement values obtained by tester 1 , and inter-rater reliability was calculated by comparing the first trial values of tester 1 and tester 2. To assess the intra-rater reliability, the infrasternal angle was measured on two different days with an interval of 2-3 days.

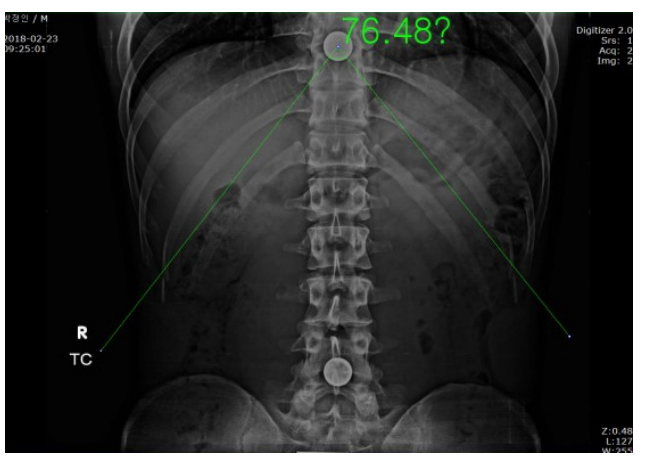

Figure 2. Radiographic measurement of the infrasternal angle. 


\section{Goniometric measurement}

To assess the validity of radiographic measurement, the infrasternal angle was measured using a universal goniometer. During the infrasternal angle measurement, we checked the medial margin as a reference point; a perpendicular line was drawn from the mid-clavicle to the medial margin of the rib cage. Markers were attached on the xiphoid process and the medial margin reference point, and the axis of the goniometer was placed a the xiphoid process (Figure 3). ${ }^{1}$ The stationary arm and movable arms were aligned along the xiphoid process and medial margin of rib cage on each side. Measurement of the infrasternal angle was conducted by tester 1 , and the mean and SD of each subject's characteristics and infrasternal angle were calculated. Repeatedmeasures analysis of variance (ANOVA) with a post hoc $t$ test was used to test for systematic bias between the first and second measurements. Intraclass correlation coefficients (ICCs: 3,1) were used to determine the inter-rater and intra-rater reliability of the infrasternal angle measurements. For the purpose of interpretation, an ICC $>0.75$ was considered "excellent", 0.40-0.75 was "fair to good", and 0.000.40 was "poor". 12 The standard error of measurement (SEM) was calculated for each measurement to assess absolute consistency $(\mathrm{SEM}=\mathrm{SD} \sqrt{ } 1-\mathrm{ICC}) .{ }^{13}$ Minimal detectable difference $\left(95 \%\right.$ confidence interval) $\left(\mathrm{MDD}^{95}\right)$ scores were calculated $\left(\mathrm{MDD}^{95}=\mathrm{SEM} \times \sqrt{2} \times 1.96\right) .{ }^{14}$ Validity was assessed using Pearson's correlation coefficient $(r)$. We defined $r>0.75$ as "excellent", $0.5-0.75$ as "good", 0.25-0.5 as "moderate", and $<0.25$ as "poor". ${ }^{15}$ The significance level was set at 0.05 . The Statistical Package for the Social Sciences for Window version 19.0 (SPSS, Inc., Chicago, IL, USA) was used for the statistical analyses.

\section{RESULTS}

The means and SDs of the infrasternal angle for each measurement technique and for testers 1 and 2 are shown in Table 1. There were no significant differences between the

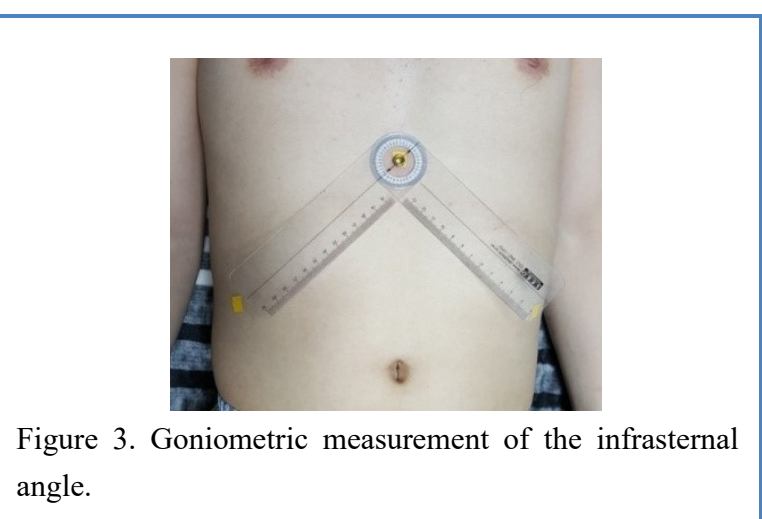

first and second radiographic measurements for tester 1 $(p=0.24)$. The intra-rater and inter-rater reliability of infrastenral angle measurement by the radiographic method were excellent. The ICCs, SEM, MDD ${ }^{95}$ are shown in Table 2. Radiographic measurement of the infrasternal angle was highly correlated with that of goniometric measurement ( $r=$ 0.85) (Table 3, Figure 4).

\section{DISCUSSION}

This study was to determine reliability and validity of measurement of infrasternal angle by radiographic method. Our result showed excellent intra- and inter-rater reliability for radiographic measurement of the infrasternal angle (0.991 and 0.993, respectively). Though tester 2 lacked measurement experience, we found excellent inter-rater reliability following sufficient pre-training of measurement method. These results suggest that reliable infrasternal angle measurement should be possible using the radiographic

Table 1. Mean and standard deviation of the infrasternal angle

\begin{tabular}{cccc}
\hline $\begin{array}{c}\text { Measurement } \\
\text { technique }\end{array}$ & Tester 1 & Tester 2 \\
\hline $\begin{array}{c}\text { Radiographic } \\
\text { measurement }\end{array}$ & First & $86.28^{\circ} \pm 11.91^{\circ}$ & $87.12^{\circ} \pm 11.95^{\circ}$ \\
Goniometric & & $86.67^{\circ} \pm 12.33^{\circ}$ & \\
measurement & & $83.36^{\circ} \pm 10.35^{\circ}$ & \\
\hline
\end{tabular}

Data are expressed as mean \pm SD.

Table 2. Intra- and inter-rater reliability of the infrasternal angle measurement by the radiographic method $\quad(\mathrm{N}=25)$

\begin{tabular}{ccc}
\hline $\begin{array}{c}\text { Radiographic } \\
\text { measurement }\end{array}$ & $\begin{array}{c}\text { Intra-rater } \\
\text { reliability }\end{array}$ & $\begin{array}{c}\text { Inter-rater } \\
\text { reliability }\end{array}$ \\
\hline ICCs $(3,1)$ & 0.99 & 0.99 \\
$95 \%$ CI & $0.98-0.99$ & $0.98-0.99$ \\
SEM & $1.13^{\circ}$ & $0.99^{\circ}$ \\
MDD & $3.13^{\circ}$ & $2.76^{\circ}$ \\
\hline
\end{tabular}

ICC: intraclass correlation coefficients, CI: confidence interval, SEM: standard error of measurement, MDD: minimal detectable difference.

Table 3. Correlation of infrasternal angle measurement between radiographic and goniometric method

$(\mathrm{N}=25)$

\begin{tabular}{ccc}
\hline & $\begin{array}{c}\text { Pearson's correlation } \\
\text { coefficient }(r)\end{array}$ & $P$-value \\
\hline $\begin{array}{c}\text { Radiographic - goniometric } \\
\text { measurement }\end{array}$ & 0.85 & 0.00 \\
\hline
\end{tabular}




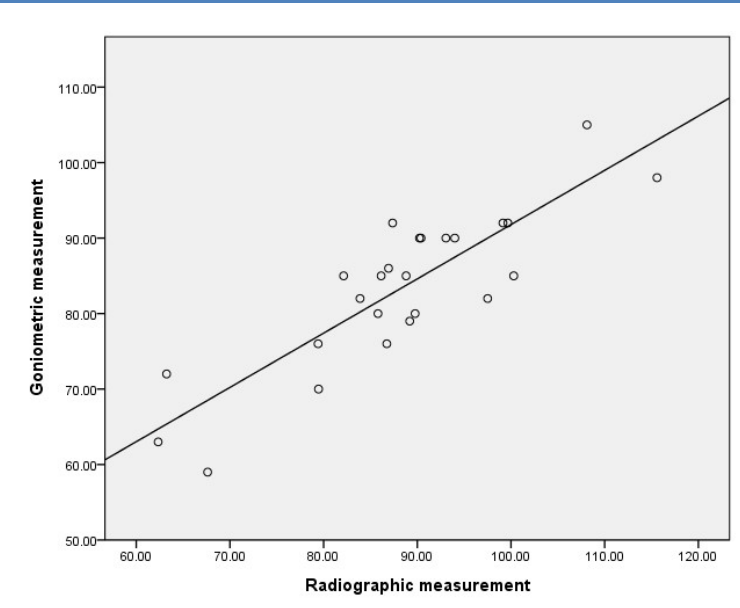

Figure 4. A comparison of infrasternal angle measured using radiographic and goniometric measurement methods. Scatter plot of infrasternal angle measured by radiographic and goniometric measurement methods.

method by identification of the xiphoid process. In radiographic imagery, the medial margin of $10^{\text {th }}$ rib is clearly observed, such that it may be used as a landmark for infrasternal angle measurement by radiographic.

In the current clinical trial, the measurement of infrasternal angle mainly uses goniometer. The mean infrasternal angle measured using the goniometer was $83.36^{\circ}$ and that measured using the radiographic method was $86.28^{\circ}$ in the first trial and $86.67^{\circ}$ in the second. Radiographic measurements of the infrasternal angle were highly correlated with goniometric measurements, and the validity of the two measurement methods was highly correlated $(r=0.85)$. Although it was difficult to determine which measurement method was more accurate, both methods appeared highly appropriate. Further studies may be required to determine which infrasternal angle assessment tools, such as computed tomography or magnetic resonance image equipment, are most accurate.

To date, it has been impossible to identify the xiphoid process in a chest AP radiographic image to measure the infrasternal angle. Thus, many studies have measured the infrasternal angle using the goniometric or photographic method. ${ }^{1}$ Kim et al. ${ }^{1}$ reported that infrasternal angle measurements acquired by the photographic method exhibited excellent intra- and inter-rater reliability. To identify the xiphoid process in chest AP radiographic images, we used a marker of the xiphoid process. Thus, the infrasternal angle measurement by the radiographic method was possible, which makes this a highly reliable and valid measurement technique.

This study had several limitations. First, the generaliza- bility of the results of this study is limited because subjects were young. Second, this study was conducted using small ( $n=25)$ samples. Thus, further studies are needed to confirm the reliability and validity of infrasternal angle measurement by radiographic methods in different age groups and larger samples. In addition, the selection of an appropriate reference point should be investigated to improve the precision of measurement by the radiographic method.

\section{CONCLUSIONS}

This study determined the reliability and validity of infrasternal angle measurement by the radiographic method. The intra- and inter-rater reliability were excellent, and the radiographic measurement was highly correlated with the goniometric measurement. Therefore, the radiographic method is a highly reliable and valid measurement method for infrasternal angle measurement.

\section{Key Points}

Question What is the reliability and validity of the infrasternal angle measured by radiographic method?

Findings The intra- and inter-rater reliability of infrasternal angle measurements taken by the radiographic method were excellent.

Radiographic measurement of the infrasternal angle was highly correlated with goniometric measurement.

Meaning The radiographic method is a highly reliable and valid tool for infrasternal angle measurement.

\section{Article information}

Conflict of Interest Disclosures: None.

Funding/Support: None.

Acknowledgment: None.

\section{REFERENCES}

1. Kim MH, Weon JH. Intra- and inter-rater reliabilities of infrasternal angle measurement. $J$ Kor Phys Ther. 2015; 27(3):154-158.

2. Neumann DA. Kinesiology of the musculoskeletal system. St. Louis, Mosby, 2002.253p.

3. De Troyer A, Wilson TA. Action of the diaphragm on the rib cage. J Appl Physiol. 2016;121:391-400.

4. Kendall FP, McCreary EK, Provance PG, et al. Muscles: Testing and function with posture and pain. $5^{\text {th }} \mathrm{ed}$. Baltimore, MD: Williams \& Wilkins; 2005.

5. Korovessis PG, Stamatakis MB, Baikousis AG. Recipro- 
cal angulation of vertebral bodies in the sagittal plane in asymptomatic Greek population. Spine. 1998;23:700-705.

6. Ewert F, Syed J, Wagner S, et al. Does an external chest wall measurement correlate with a CT-based measurement in patients with chest wall deformities? Journal of Pediatric Surgery. 2017;52(10):1583-1590.

7. Shaalan AM, Kasb I, Elwakeel EE, et al. Outcome of surgical repair of pectus excavatum in adults. Journal of Cardiothoracic Surgery. 2017;12(1):72.

8. Szopa A, Domagalska-Szopa M. Correlation between respiratory function and spine and thorax deformity in children with mild scoliosis. Medicine. 2017;96:22.

9. Richardson C, Hodges PW, Hides J. Therapeutic exercise for lumbopelvic stabilization: A motor control approach for the treatment and prevention of low back pain. $2^{\text {nd }} \mathrm{ed}$. London: Churchill Livingstone; 2004.

10. Sahrmann SA. Diagnosis and treatment of movement impairment syndrome. New York, USA: Mosby; 2002.

11. Sahrmann SA. Movement system impairment syndromes of the extremities, cervical and thoracic spines. St Louis: Elsevier; 2011.

12. Crossley KM, Bennell KL, Cowan SM, et al. Analysis of outcome measures for persons with patellofemoral pain: Which are reliable and valid? Arch Phys Med Rehab. 2004;85(5):815-822.

13. Ha SM, Kwon OY, Weon JH, et al. Reliability and validity of goniometric and photographic measurements of clavicular tilt angle. Man Ther. 2013;367-371.

14. Ries JD, Echternach JL, Nof L, et al. Test-retest reliability and minimal detectable change scores for the timed "up \& go" test, the six-minute walk test, and gait speed in people with Alzheimer disease. Phys Ther. 2009; 89(6):569-579.

15. Alanay A, Cil A, Berk H, et al. Reliability and validity of adapted Turkish version of scoliosis research society22 (SRS-22) questionnaire. Spine. 2005;30(21):24642468. 